تأثير اسيد جيبرليك، دما و كشت جنين بر شاخصهاى جوانهزنى بذر در كَنههاى مختلف زرشك (Berberis spp.)

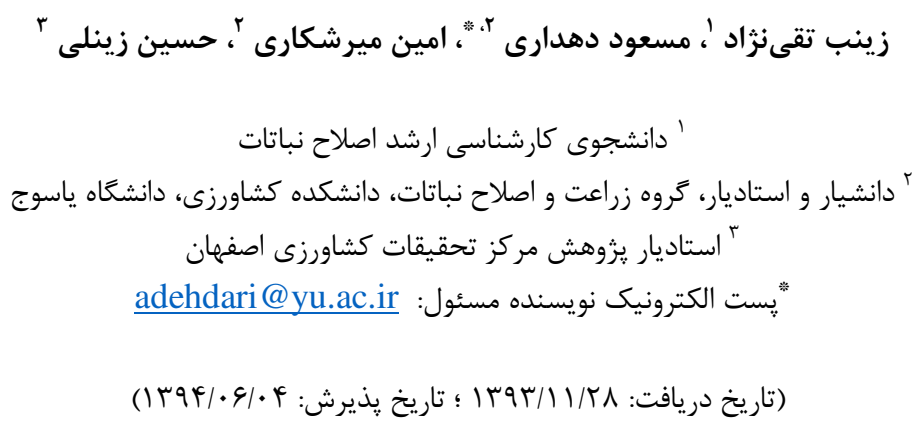

جكيده

كياه دارويى زرشك، متعلق به تيره زرشك است. بذرهاى گياه زرشك داراى دوره خواب طولانى هستند؛

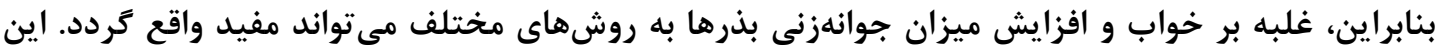

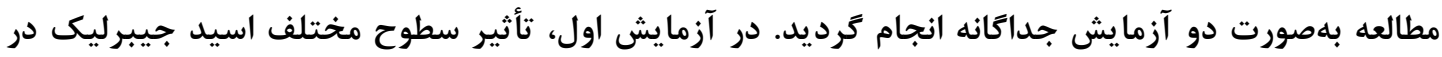

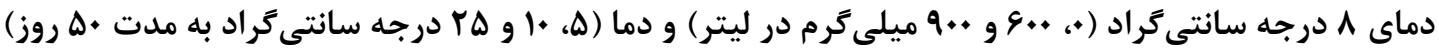

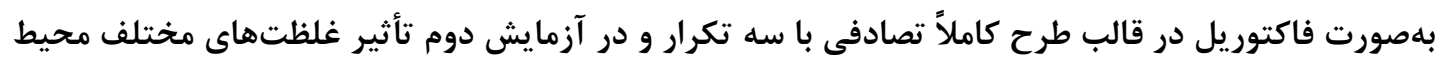

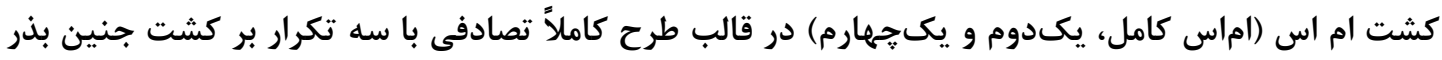

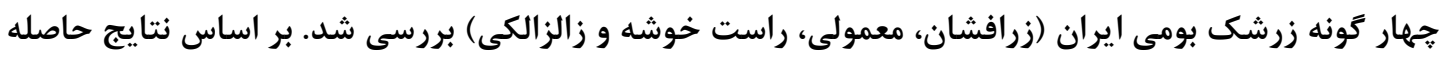

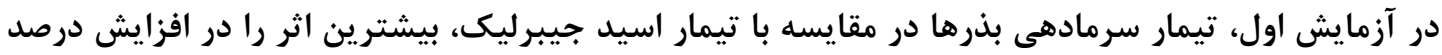

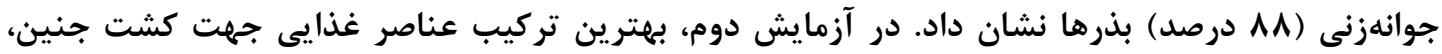
محيط كشت اماس كامل بود. بهَّونهاى كه در هر جهار كونه بعد از دو يا سه روز جوانهزنى ..ا درصد مشاهده كرديد. در مجموع بهترين روش براى جوانهزنى سريع زرشك، در همه كونههاى مورد مطالعه استفاده از كشت جنين در محيط كشت اماس كامل تشخيص داده شد. وازههاى كليدى: جيبرليك اسيد، خواب بذر، كَياه دارويى، محيط كشت

بذرها، به روشهاى مناسب براى شكست خواب و افزايش درصد جوانهزنى بذرها دست يابند. خواب اوليه

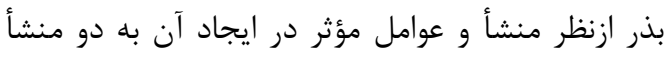
درونى و بيرونى تقسيم مىشود (رجبيان و همكاران، .(1)人

خواب بذر در شرايط نامساعد رويشى سودمند است،

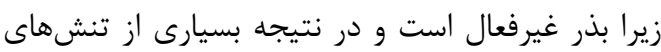

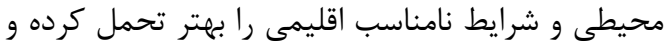

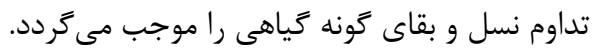

مقدمه يكى از موانع عمده كاشت كياهان دارويى در خارج

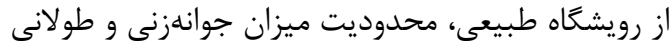

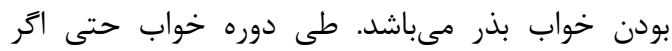
شرايط مناسب محيطى (رطوبت، دما، نور و غيره) نيز

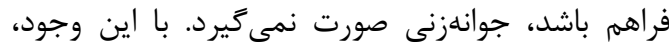

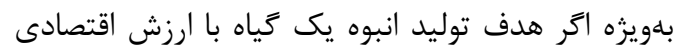

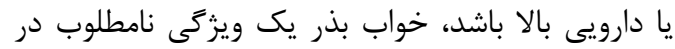
نظر كرفته مىشود (رجبيان و همكاران، ع^ץ ())؛ بنابر اين

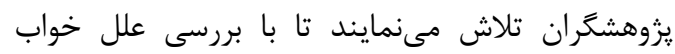


توسعهنيافته ذكر نمود؛ بنابراين توصيه كرد كه بايستى كياهان مادرى در شرايط كنترلشده يا كلخانه كشت

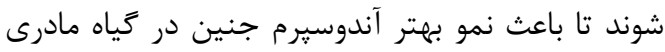
شده و در نتيجه باعث رشد بهتر جنين شود.

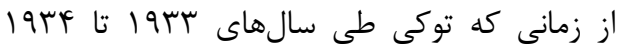
توانست جنين بدون آندوسيرم كياهان هستهدار را نجات داده و دانهالهاى زنده از آنها به دست آورد، كشت جنين ييشرفت قابلملاحظهاى كرده و تاكنون ارقام متعددى در دنيا با استفاده از اين روش توليد شدهاند

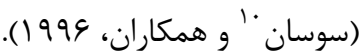
از طرفى ديگر با توجه به طولانى بودن مراحل

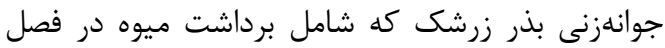
رسيدن ميوه، حذف ميانبر و برونبر ميوهها، سرمادهى

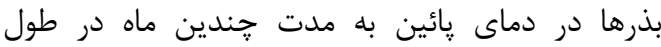

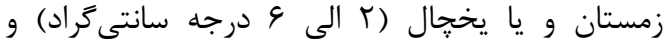
جوانهزنى بذرها در بهار آينده است، دانهال جندين

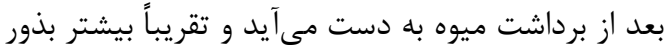

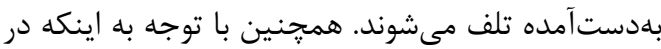

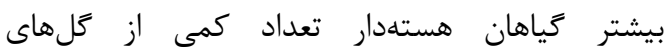
كردهافشانى شده به ميوه تبديل مى شوند (فتحى و

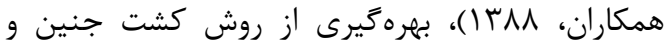
كمك به جوانهزنى جنينها در شرايط درون شيشهاي الى بهمنظور غلبه بر اين مشكلات و دستيابى به دانهال هاى

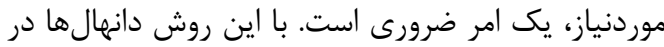

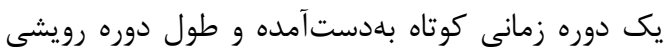

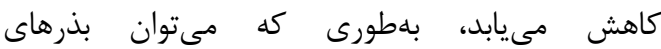
جمعآورىشده در طول همان فصل (بهشرط رسيدگى كامل) را وادار به جوانهزنى كرد.

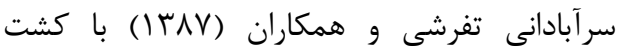
جنين در محيط كشت 1/4 MS توانستند خواب بذر در

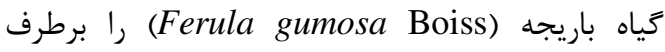

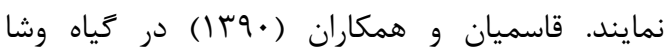
(Dorema ammoniacum) به نتايج مطلوبى در محيط 1/4 MS دست يافتند.

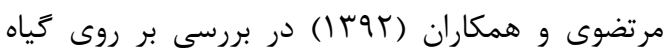
جويل (Ferulago angulata) تزارش كردند كه يكى نران

\footnotetext{
${ }^{10}$ Susan
}

تحقيقات نشان داده است كه بسيارى از تنظيمكنندههاى رشد كياهى از جمله اكسين، جيبرلين، آنساء سيتوكينين، اتيلن و اسيد آبسيزيك شايد از مسيرهاى مشخصى كه منجر به كنترل عملكرد اسيد نوكلئيكها مىشوند، در تحريك جوانهزنى و يا خواب بذر نقان النش

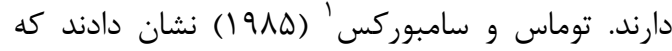
جيبرلينها در بذور كرفس مقدار ساير تنظيمكنندههاى رشد و همجنين جريان برخى يونها از جمله يتاسيم و

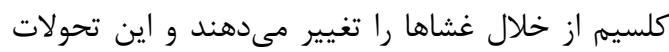
موجب انتقال بيامهاى ويزه و تحريك سنتز يا فعاليت

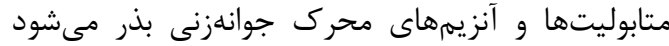

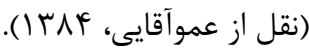

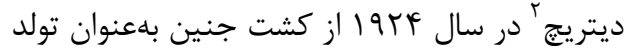

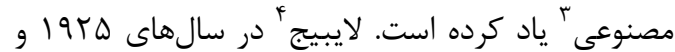
1949 توانست جنين بذر كتان را كشت داده و كياه

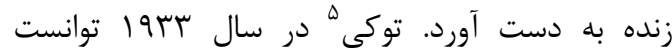

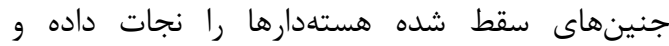

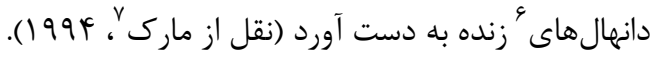

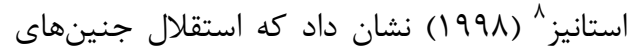
جداشده زمانى محقق مىشود كه تمايز جنين، انجام و

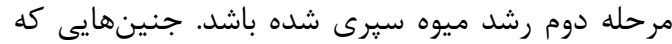
در شرايط طبيعى به اين مرحله رشدى نرسيده باشند،

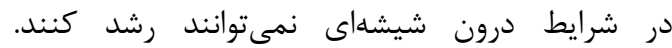

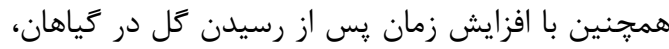

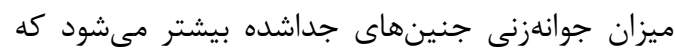

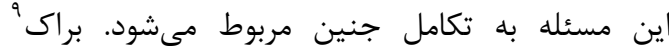
(19V^) در كشت درون شيشاءى را، مرحله رشدى جنين دارئ دانسته

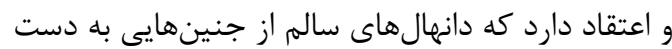
مى آيد كه رشد كافى داشته باشند. ايشان دماى دارئه بائين

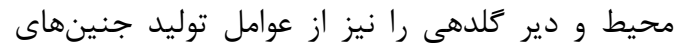

\footnotetext{
${ }^{1}$ Tomas and Samborcss

${ }^{2}$ Dietrich

${ }^{3}$ Artificial birth

${ }^{4}$ Laibach

5 Tukey

${ }^{6}$ Seedling

${ }^{7}$ Mark

${ }^{8}$ Stanys

${ }^{9}$ Beraak
} 
آزمايش اول: تأثير اسيد جيبرليك و دما بر

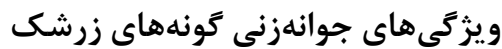

در اين آزمايش شش تيمار شامل محلولهايى با

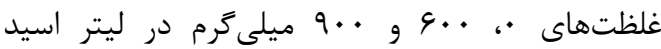
جيبرليك در دماى ^ 1 درجه سانتى كراد و سه تيمار

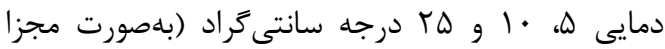
يعنى در مجموع شش تيمار) بر جوانهزنى جهار كونه

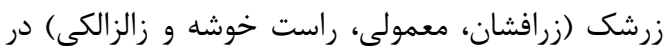
سه تكرار بررسى شد. براى تيمارهاى اسيد جيبرليك،

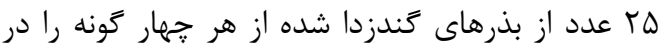
هر كدام از محلولهاى فوق غوطهور و به مدت آندان ساعت روى شيكر قرار داده شدند. پِ از آن آن بذرها از محلولها خارج و در ظروف يترى محتوى كاغذ صافى و دان دان

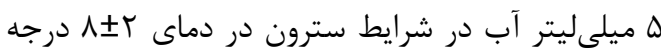

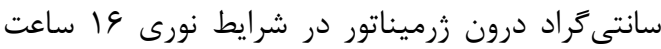

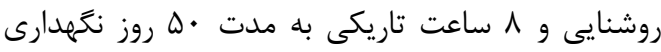

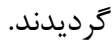

براى اعمال تيمار دمايى، بذرهاى كَندزدا شده جهار كونه زرشك را درون ظرف يترى و روى روى كاغذ صافى دافي

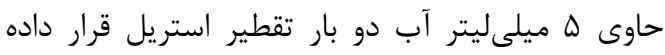

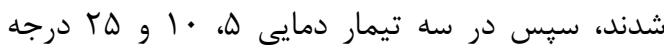
سانتى كراد در زرميناتورهاى جداكانه در شرايط نورى

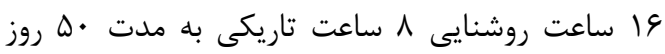

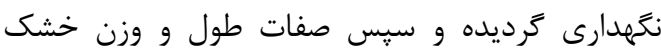
اندام هوايى، طول و وزن خشك ريشه و درصد جوانهزنى

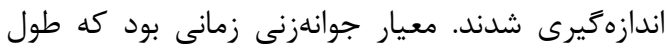
ريشه קه دو ميلىمتر رسيده باشد.

آزمايش دوم: كشت جنين در شرايط درون شيشهاى بامنظور انتخاب مناسبترين غلظت محيط كشت از محيط كشت يايه MS كامل (موراشيخ و

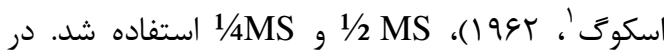
اين مرحله با استفاده از بهترين محلول كَندزدا، ريز

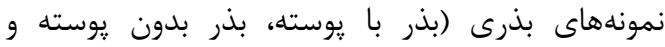

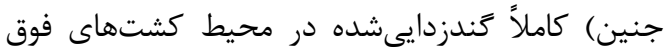

از بهتر ين روشها جهت جوانهزنى سريع اين كياه، كشت

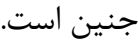

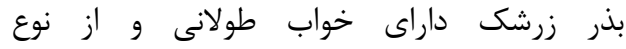
فيزيولوزيكى است. سرمادهى تا حد زيادى مىتواند به رفع اين خواب كمك كند. رضايى و بالندرى (1) (1)، كزارش دادند بهترين تيمار جهت شكست خواب بذور

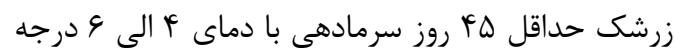
سانتى كراد است. راهحل ديكر رفع اين مشكل، كشت رتش

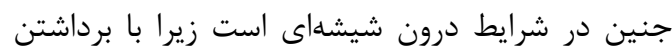

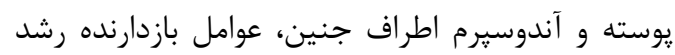
برطرف شده و جوانهزنى سريعتر صورت مى تئيرد

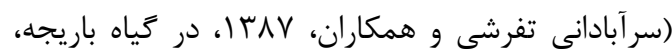

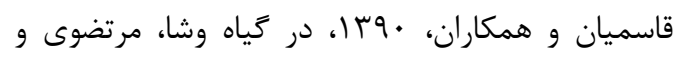

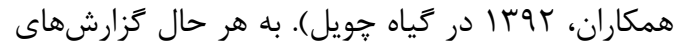
كمى در خصوص بهبود جوانهزنى بذر كياه زرشك بهوئه از طريق كشت جنين و اسيد جيبرليك در دسترس برس است، به همين دليل اين يزوهش با بهكاركيرى جهار كونه زرشك و روشهاى مختلف شكستن خواب بذر برد طراحى و اجرا گرديد.

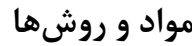 مواد كياهى}

بذرهاى جهار كَونه زرشك بومى ايرى ايران در سال

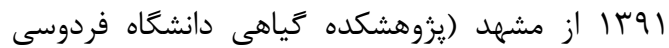
مشهد) و اصفهان (مركز تحقيقات شهيد فوزوه) جمع آورى شدند. بذور به مدت يك دقيقه در محلول اتانل • V درصد قرار كرفتند، سيس براى كندزدايى، شستشو با جريان

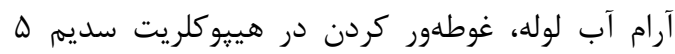

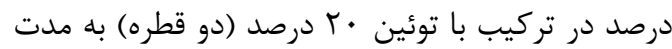

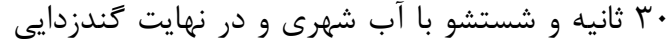

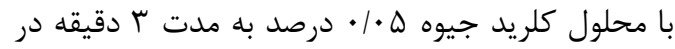

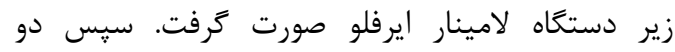

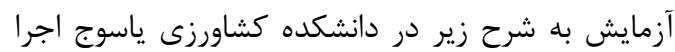

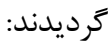

\footnotetext{
${ }^{1}$ Murashige and Skoog
} 
LSmeans 9/1 و 9xcel براى تجزيه و تحليل و رسم نمودارها

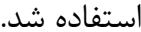

نتايج و بحث

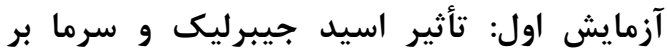

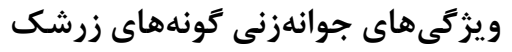
جدول تجزيه واريانس (جدول () نشان داد كه كونههاى مختلف تأثير معنى دارى بر روى همانه صدات

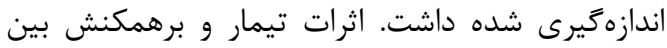

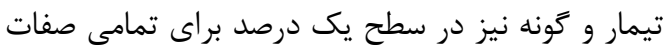
مورد بررسى معنى دار شد.

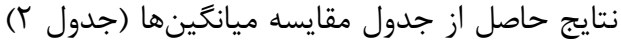
نشان داد كه براى صفت طول اندام هوايى، بلندترين

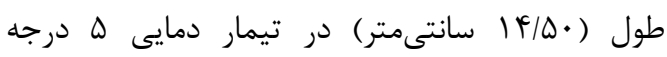

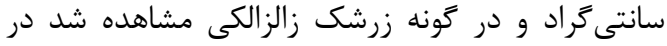

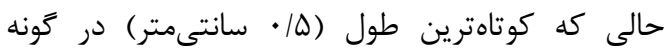

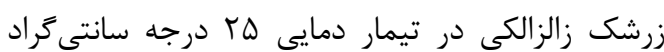
بود. براى صفت وزن خشك اندام هوايى، بيشترين وزن درن

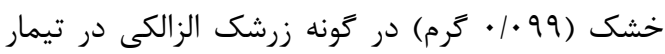

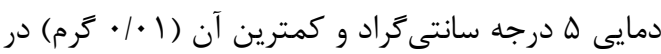

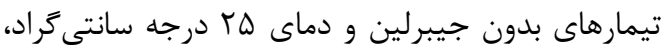
در جهار گونه مورد مطالعه بود.
كشت گرديدند. بعد از كشت ريز نمونهها، ظروف كشت در قفسههاى اتاقى رشد با دوره نورى 19 به به 1 (به

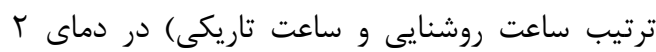

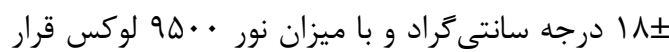
جهار الى ينج هفته يس از كاشت ريزنمونه (جنين سالم)، صفات درصد ساقهزايى، تعداد ساقه، طول اندام هوايى (سانتىمتر)، وزنتر اندام هوايى (ميلى (نرم)، وزن

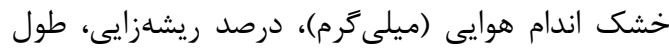
ريشه (سانتىمتر)، وزنتر ريشه (ميلى ريشه (ميلى

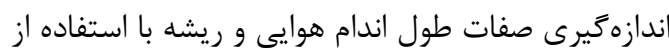

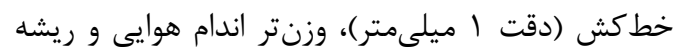

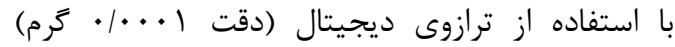

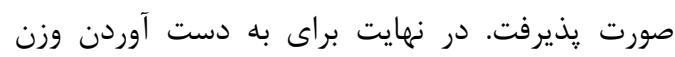

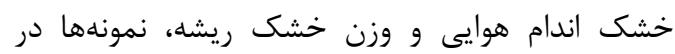

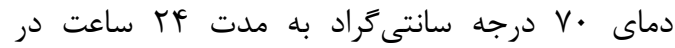

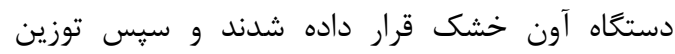

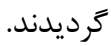

\section{تجزيه و تحليل آمارى دادهها}

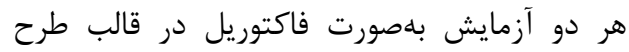

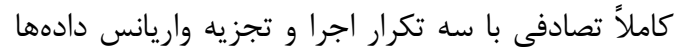

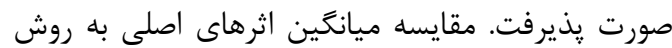

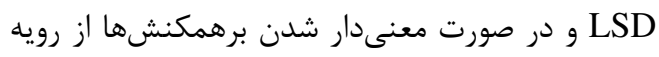

جدول ا- ميانكَين مربعات منابع تغيير براى صفات مورد بررسى زرشك در تيمار غلظتهاى مختلف اسيد جيبرليك و دما

\begin{tabular}{|c|c|c|c|c|c|c|}
\hline درصد جوانهزنى & وزن خشك ريشه & طول ريشه & وزن خشك اندام هوايى & طول اندام هوايى & درجه آزادى & منابع تغيير \\
\hline$\wedge 9 \Delta F / 1^{* *}$ & $\cdot|\cdot \Delta|^{* *}$ & $r q q / \varepsilon r^{* *}$ & $\cdot / \cdot \wedge r^{* *}$ & $r \cdot r / \Delta \cdot{ }^{* *}$ & $\Delta$ & تيمار \\
\hline $\mid \Delta \Delta / r^{* *}$ & $\cdot|\cdots|^{* *}$ & $1 \cdot \cdot 1 \cdot 9^{* *}$ & $\cdot \mid \cdots 1^{* *}$ & r/qr** & r & كونه \\
\hline$r \cdot /^{* *}$ & $\cdot / \cdots r^{* *}$ & $\Gamma / \Delta \cdot{ }^{* *}$ & $\cdot / \cdots r^{* * *}$ & $9 / 9 r^{* *}$ & 10 & تيمار×كونه \\
\hline $11 / \pi$ & $\cdot \mid \cdots \cdot 1$ & $.1 \cdot 9$ & $\cdot \mid \cdots \cdot 1$ & $\cdot / K F$ & is & خطا \\
\hline $9 / 71$ & $19 / \mathrm{VQ}$ & $V / \Delta)$ & V/A & $1 \cdot / 11$ & & تغيرات (در \\
\hline
\end{tabular}


جدول r - مقايسه ميانكَين برهمكنش تيمار غلظتهاى مختلف اسيد جيبرليك و دما و جهار گونه زرشك براى صفات مورد بررسى

\begin{tabular}{|c|c|c|c|c|c|c|c|}
\hline جوانهزنى درص & ريشه (كَرم) & (سانتى متر) ريشه & وزن خدام هوايى & 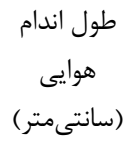 & گونه زرشك & & تيمار \\
\hline $\mid f / v a$ & $\cdot / \cdot f a$ & $\cdot 10 \cdot a$ & $\cdot / \cdot 1 \mathrm{a}$ & $1 / \pi a$ & زرافشان & \multirow{4}{*}{$(\cdot)$} & \multirow{12}{*}{ جيبر دريك } \\
\hline $\mid 9 / \cdot \mathrm{a}$ & $\cdot 1 \cdot 1 \cdot \mathrm{a}$ & $\cdot / v \Delta \mathrm{a}$ & $.1 \cdot 1 \mathrm{a}$ & $r / \cdot a$ & معمولى & & \\
\hline $1 r / r a$ & $\cdot / \cdot 1 \cdot \mathrm{a}$ & $\cdot 10 \cdot a$ & $.1 .1 \mathrm{a}$ & $1 / \cdot a$ & راست خوشه & & \\
\hline$q / r b$ & $\cdot 1 \cdot \cdot r a$ & $\cdot 10 \cdot a$ & $.1 \cdot 1 \mathrm{a}$ & $1 / \cdot a$ & زالزالكىى & & \\
\hline$r \Delta / r b$ & $\cdot 1 \cdot 1 \cdot \mathrm{a}$ & $1 / r r a$ &.$/ \cdot r a$ & r/Aa & زرافشان & \multirow{4}{*}{$(\varphi \cdot \cdot)$} & \\
\hline rr/ra & $\cdot / \cdot 1 \cdot \mathrm{a}$ & $1 / \cdot \cdot a$ &.$/ \cdot c b$ & $r / r b$ & معمولى & & \\
\hline$r \cdot / \mathrm{Va}$ & $\cdot 1 \cdot 1 \cdot \mathrm{a}$ & $1 / \cdot \cdot a$ & $\cdot / \cdot \Delta c$ & $r / \Delta \mathrm{a}$ & راست خوشه & & \\
\hline rT/VC & $\cdot 1 \cdot 1 \cdot \mathrm{a}$ & $\cdot / \Delta \cdot b$ & $\cdot / \cdot r \mathrm{~d}$ & $f / r a$ & زالزالكى & & \\
\hline $\mathrm{FF} / \cdot \mathrm{c}$ & $\cdot 1 \cdot t \cdot a$ & r/s Va & $\cdot / \cdot \mathrm{Hc}$ & $V / \cdot b$ & زرافشان & \multirow{4}{*}{$(9 \cdots)$} & \\
\hline $991 \cdot \mathrm{a}$ & $\cdot 1 \cdot r \cdot b$ & $r / l V b$ & $\cdot / \cdot r c$ & $\Delta / \cdot C$ & معمولى & & \\
\hline$r F / \cdot d$ & $\cdot 1 \cdot 1 \cdot \mathrm{c}$ & $1 / \pi r c$ & $\cdot / \cdot \Delta b$ & $\mathrm{f} / \mathrm{rd}$ & راست خوشه & & \\
\hline$\Delta F / \cdot b$ & $\cdot / \cdot 1 \cdot \mathrm{c}$ & $1 / r r c$ & $\cdot 1 \cdot 9 \mathrm{a}$ & $\Lambda / r a$ & زالزالكى & & \\
\hline G/Vc & $\cdot 1 \cdot 1 \cdot \mathrm{a}$ & $1 / \cdots a$ &.$/ .99$ & $1 / \mathrm{ra}$ & زرافشان & \multirow{4}{*}{$(T \Delta)$} & \multirow{12}{*}{ سانتى (درجاد 1 (داد) } \\
\hline $\mid F / v b$ & $\cdot / \cdot 1 \cdot \mathrm{a}$ & - Ifra & $\cdot 1 \cdot 1 \mathrm{a}$ & $\cdot / \wedge \mathrm{a}$ & معمولى & & \\
\hline $\mathrm{IV} / \mathrm{ra}$ & $\cdot / \cdot 1 b$ & $\cdot \mid q \mathrm{Va}$ &.$/ \cdot 1 \mathrm{a}$ & $\cdot / 9 \mathrm{a}$ & راست خوشه & & \\
\hline$\Delta / r d$ & $\cdot / \cdot$ rbn & $\cdot 10 \cdot a$ & $\cdot / \cdot 1 \mathrm{a}$ & $\cdot / \Delta \mathrm{a}$ & زالزالكى & & \\
\hline$r F / v a$ & $\cdot 1 \cdot r \cdot a$ & $1 \cdot / 1 \mathrm{Va}$ & $.1 .9 \mathrm{a}$ & s/ra & زرافشان & \multirow{4}{*}{$(1 \cdot)$} & \\
\hline$r q / V b$ & $\cdot / \cdot r \cdot a$ & $\mathrm{~V} / \mathrm{IVb}$ & $\cdot / \cdot c b$ & s/^a & معمولى & & \\
\hline$r \mid / r b c$ & $\cdot 1 \cdot r \cdot a$ & $q / a \cdot b$ &.$/ \cdot c b$ & $\Delta / \Gamma \mathrm{b}$ & راست خوشه & & \\
\hline $1 \mathrm{~N} / \mathrm{Vc}$ & $\cdot / \cdot r \cdot \mathrm{a}$ & $\Delta / \Delta \cdot c$ &.$/ \cdot \mathrm{rc}$ & $r / r c$ & زالزالكى & & \\
\hline$\Lambda \Lambda / \cdot a$ & $\cdot / \cdot \Delta \mathrm{a}$ & $|f /| v a$ & $\cdot / \cdot v c$ & $11 / \mathrm{rc}$ & زرافشان & \multirow{4}{*}{$(\Delta)$} & \\
\hline$\wedge \vee / V a b$ & $\cdot / \cdot \Delta \mathrm{a}$ & $11 / 9 \mathrm{Vb}$ & $.1 \cdot 9 \mathrm{~d}$ & $9 / r d$ & معمولى & & \\
\hline$\Lambda r / v b$ & $.1 .9 \mathrm{a}$ & $1 \cdot 10 \cdot c$ & $\cdot / \cdot \wedge b$ & $\mid r / r b$ & راست خوشه & & \\
\hline$\Lambda N / \cdot a$ & $\cdot / \cdot \wedge \mathrm{a}$ & $\mid f / a \cdot a$ & $\cdot 11 \cdot \mathrm{a}$ & $\mid r / \Delta a$ & زالزالكى & & \\
\hline
\end{tabular}

حروف مشترك در هر ستون نشاندهنده عدم اختلاف معنىدار بر اساس آزمون LSD است •

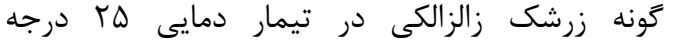
سانتى گراد ديده شد. بهطور متوسط با افزايش غلظت

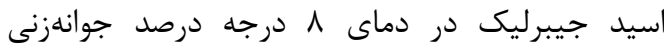

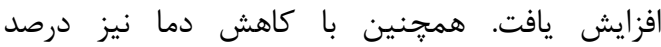
جوانهزنى بهطور קُشمخيرى افزايش نشان داد. در

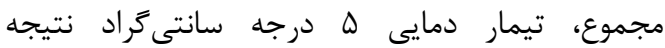
موفقترى نسبت به ديگر تيمارهاى مورد بررسى نشان داد. همجنين گونه زرشك زالزالكى نسبت به ديه ديكر

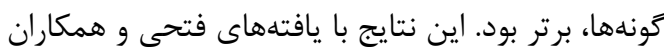
(I IMN)

دوم ميوه به دوره خواب وارد مىشوند مطابقت دارد.
براى صفت طول ريشه، در تيمار دمايى ه درجه سانتى

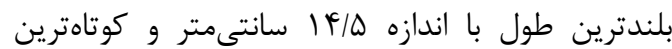

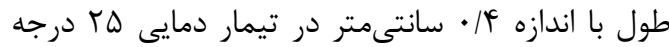
سانتى

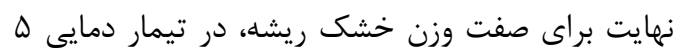
درجه سانتى

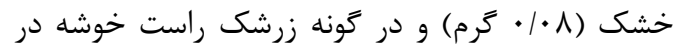
دماى له درجه سانتى

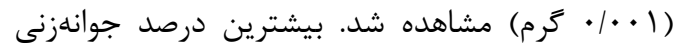

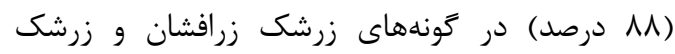

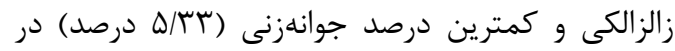


خود توجيهى براى شكستن بذر مىباشد. هدايتىه و

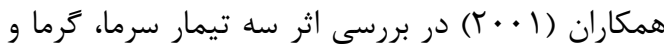
جيبرليك اسيد بر روى شكستن خواب بذر خيان 1) مؤثرترين تيمار Symphoricarpos orbiculatus

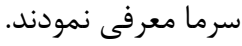

آزمايش دوم: غلبه بر خواب بذر از طريق كشت

جنين

r تا r روز پس از كشت، كليه جنينها در هر جهار

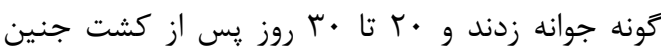
كياهجههايى كامل با بنيه مناسب توليد شدند (شكل () ). بر اساس جدول تجزيه واريانس، براى تمامى صفات

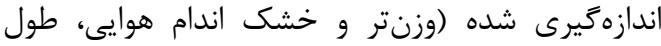
اندام هوايى، تعداد ساقه، تعداد برك، وزنتر و خشك أنى

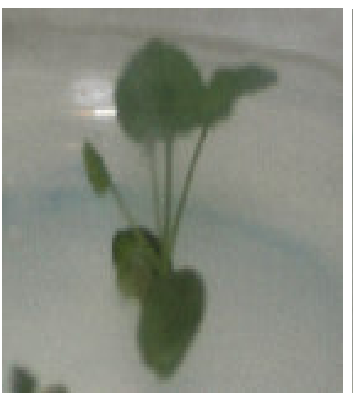

$\varphi$

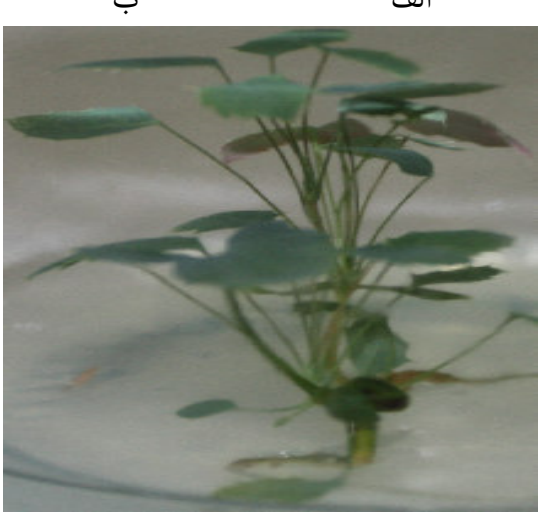

ج

شكل ا- توليد كياهجه كامل با استفاده از كشت جنين در شرايط

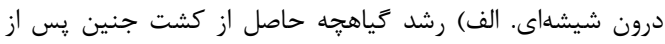

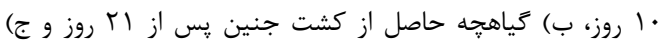

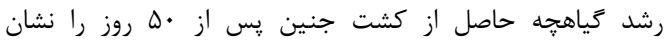

مى دهند.

${ }^{5}$ Hidayati
مقايسه نتايج بلدستآمده از تيمارهاى اسيد جيبرليك

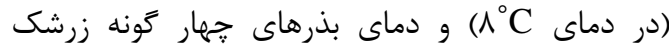

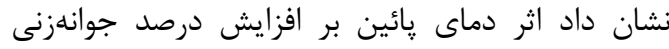
بذرهاى اين كياه بيشتر از سطوح هورمونى مورد استفاده مؤثر است. با توجه به اين نتايج احتمال داده مىشود كه كهاء عامل سرما علاوه بر تحريك سنتز جيبرليك اسيد درونزا، محركهاى ديخرى را فعال مى كند كه موجب افزايش سرعت جوانهزنى بذرها مئركردد (عموآقايى،

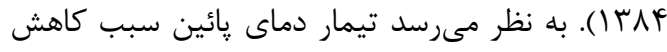

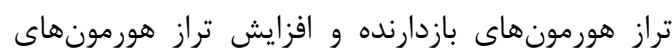
محرك شده و بدين ترتيب سبب افزايش ريتانسيل جوانهزنى بذر مىشود. اين رويدادها بهطور همزمان رئر

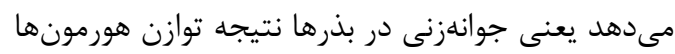

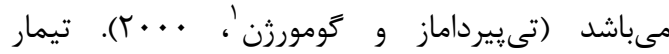
سرمادهى بذرها در مقايسه با بيش تيمار جيبرليك اسيد (در دماى

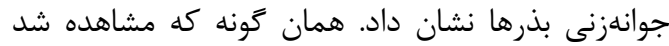
بذرهاى زرشك بومى ايران خواب فيزيولوزيك از خود

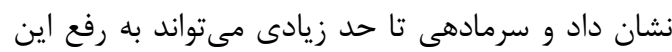

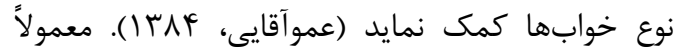

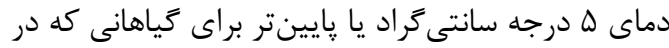
اقليمهاى سرد مىرويند بيشترين تأثير را در شكست درائن

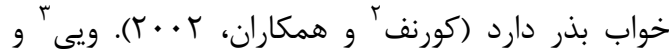

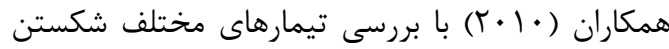
خواب بر روى بذر Solanum rostratum كزارش كردند كه خواب مكانيكى بلهوسيله تيمار اسيد

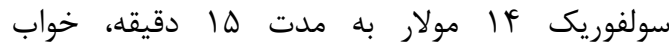

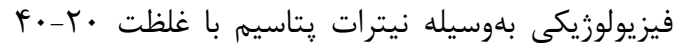

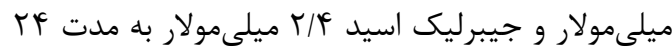

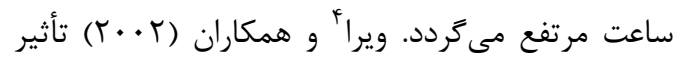

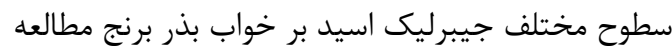

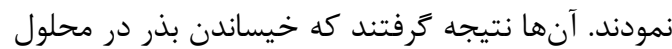

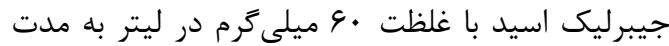
ع r ساعت براى شكستن بذر بهترين تيمار مى باشد.

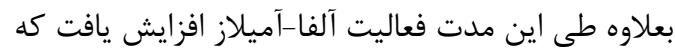

\footnotetext{
${ }^{1}$ Tipirdamaz and Gomurgen

${ }^{2}$ Koornneff

${ }^{3}$ Wei

${ }^{4}$ Vieira
} 
همجنين كمترين وزن خشك (ه ( • |• گرم) نيز در كونه زرشك زالزالكى به ترتيب در تيمارهاى MS 童 MS

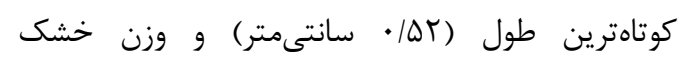

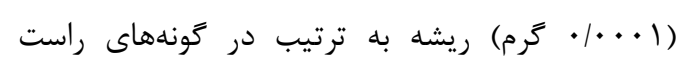

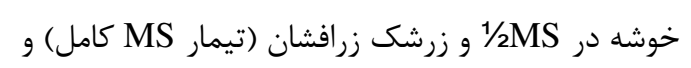
زرشك زالزالكى (تيمار MS

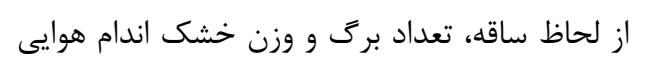
تيمار MS كامل و همجنين براى صفت طول اندام ندام هوايى تيمار MS همان كونه كه نتايج نشان داد كياهجهها در تيمار

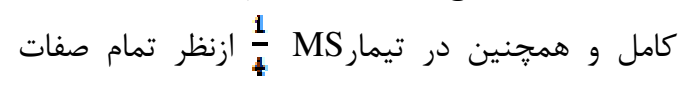
اندازمخيرى شده نسبت به محيطهاى ديخر به كاررفته در

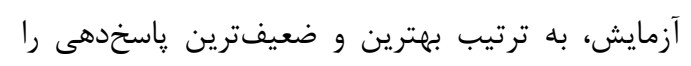

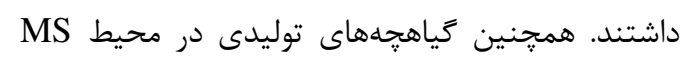

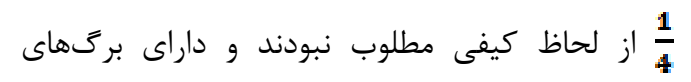

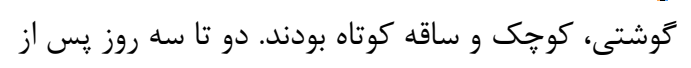

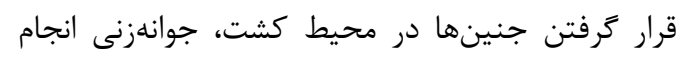
شد كه در مقايسه با روش كشت بذر (يوستهدار و بدون إندان

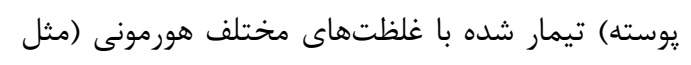

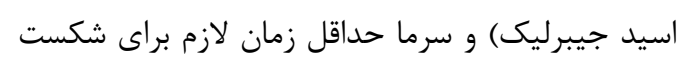

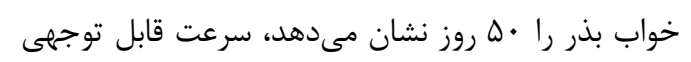

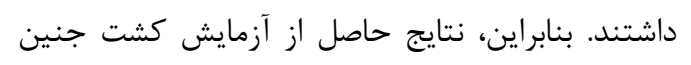

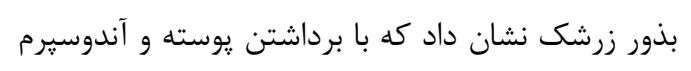

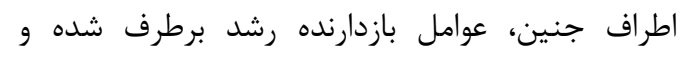

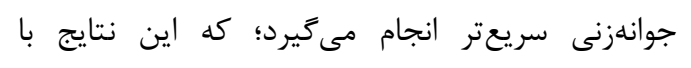

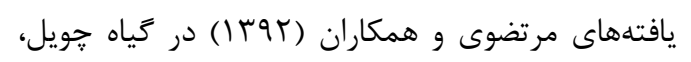

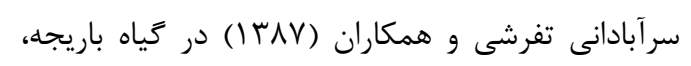

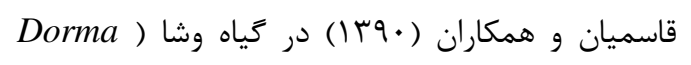
(ammoniacum

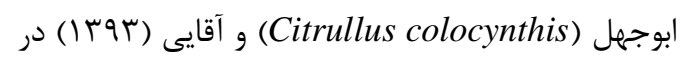

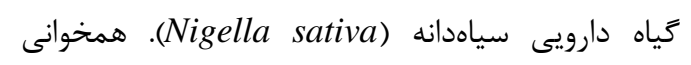
داشت.
جدول ب - ميانكين مربعات منابع تغيير براى صفات ارزيابىشده در

\begin{tabular}{|c|c|c|c|}
\hline & & جنين زرشك & كشت درون شيشهاي \\
\hline ساقداد & طول اندام هوايى & درجه آزادى & منابع تغيير \\
\hline$\cdot \mid \mathcal{F} \Lambda^{* * *}$ & $r) / \cdot 9^{* * * *}$ & r & محيط كشت \\
\hline $1 / V \curlyvee \Lambda^{* * *}$ & $r \mid / r q^{* * * *}$ & r & كَونه \\
\hline $1 /\left.T \Delta\right|^{* \text { **: }}$ & $q / 4 q^{* * * *}$ & 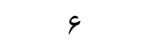 & محيط كشت×گَونه \\
\hline (ITt. & $.1 \cdot 9$ & rt & خطا \\
\hline$|\Delta / \varphi|$ & $V / \Delta F$ & & ضريب تغييرات \\
\hline
\end{tabular}

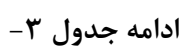

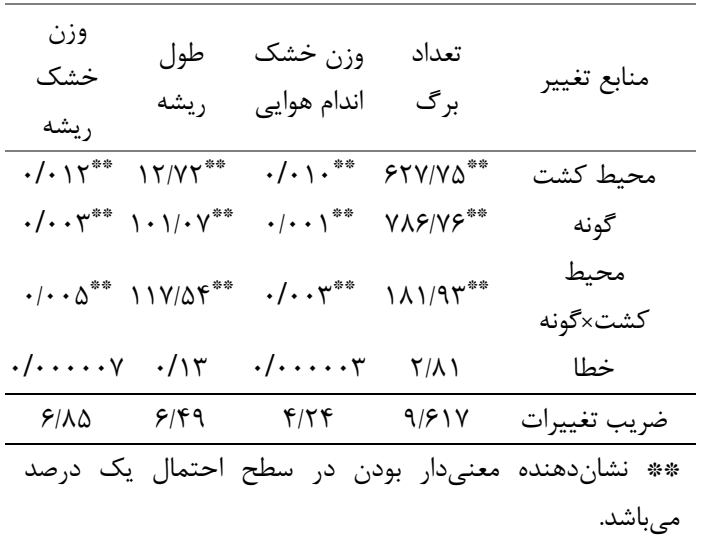

ريشه و طول ريشه) اثر محيط كشت، كونه و برهمكنش

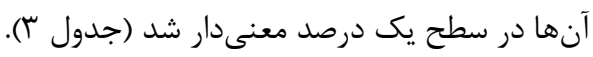

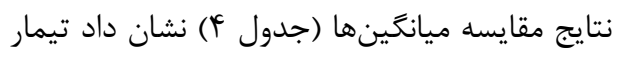

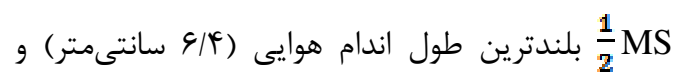
تيمار سانتىمتر ) را در كونه زرشك نشان داد.

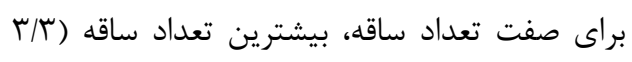
عدد) و كمترين آن (يك عدد) در كونه زرشك راست بند خوشه نيز به ترتيب در تيمارهاى MS كامل و و

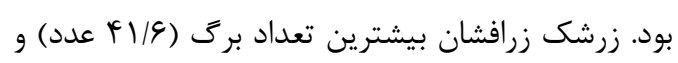

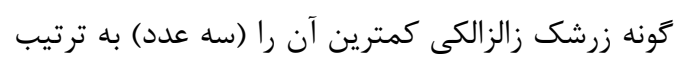
در تيمارهاى MS كامل و MS

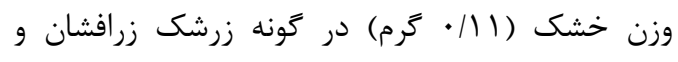


جدول F- مقايسه ميانكَين برهمكنش غلظتهاى مختلف محيط كشت اماس و جهار كونه زرشك براى صفات مورد بررسى در كشت درون

شيشهاى جنين زرشك - مقاسه مياكين

\begin{tabular}{|c|c|c|c|c|c|c|c|}
\hline رويشه (َرم) & (سانتىمتر ) & هوايى (كَرم) & تعداد برك & تعداد ساقه & طول هول اندام & كونه زرشك & كشت MS محيط \\
\hline$\cdot / / \Delta \wedge a$ & N/T\&C &.$/ \mathrm{ra}$ & $\mid q 1 / 9 a$ & $r / 4 \mathrm{bc}$ & $\Delta / \Gamma \mathrm{b}$ & زرافشان & \multirow{4}{*}{ MS } \\
\hline.$/ \cdot \Delta \wedge d$ & f/Tre &.$/ 1 \mathrm{a}$ & $11 \mathrm{e}$ & $r b$ & $\Delta / \sim \mathrm{b}$ & معمولى & \\
\hline $.1 .9 \Delta \mathrm{c}$ & $r / T \wedge f$ & $.1 . \mathrm{He}$ & $19 / 9 \mathrm{~cd}$ & $r / r a b$ & $f / q_{C}$ & راست خوشه & \\
\hline.$/ .9 \mathrm{~g}$ & r/aqe &.$/ \cdot r f g$ & $1 \mathrm{r} / \mathrm{re}$ & rb & $\mathrm{r} / \cdot \mathrm{cd}$ & زالزالكى & \\
\hline ./.rrf & $r / r r f$ &.$/ \cdot \Delta d$ & rqa & $r / 9 b c$ & $f / M c$ & زرافشان & \multirow{4}{*}{ MS } \\
\hline$\cdot / \cdot v g$ & $r / \Delta, f$ & $\cdot / \cdot \mathrm{rf}$ & $I V / r c$ & $1 / 9 \mathrm{de}$ & $r / r d$ & زرشك معمولى & \\
\hline$\cdot / \cdot \wedge r b$ & $11 / s \times b$ & $.1 .9 \mathrm{c}$ & $1 \cdot /$ ref & $1 / 9 \mathrm{~cd}$ & $f / M c$ & راست خوشه & \\
\hline . l. tre & $\Delta / 19 \mathrm{~d}$ & $\cdot / \cdot \mathrm{vb}$ & $r \& b$ & $\mathrm{ra}$ & $s / \mathrm{Fa}$ & زالزالكى & \\
\hline$\cdot / \cdot \wedge \mathrm{g}$ & $r \cdot / \Delta \cdot a$ &.$/ .1 \mathrm{~g}$ & $1 r / r d e$ & red & $r . \Delta c$ & زرافشان & \multirow{4}{*}{$\frac{2}{4} \mathrm{MS}$} \\
\hline.$/ \cdot 1 \wedge f$ & $r / 4 v e$ & $\cdot / \cdot \mathrm{rfg}$ & $1 r / 9 \mathrm{cde}$ & le & 1/9e & معمولى & \\
\hline$\cdot / \cdots / \mathrm{h}$ & $r / \backslash \varphi f$ &.$/ \cdot \mathrm{hh}$ & s/sfg & le & $r / f e$ & راست خوشه & \\
\hline$\cdot / \ldots / \mathrm{h}$ & $\cdot / \Delta T g$ & $\cdot / \cdot \Delta \mathrm{i}$ & rg & $1 / 9 \mathrm{de}$ & $\cdot / 4 \mathrm{f}$ & زالزالكى & \\
\hline
\end{tabular}

در هر ستون ميانكينهايى كه حداقل داراى يك حرف مشابه هستند ازنظر آمارى بر اساس آزمون L.S.Means در سطح قينج درصد تفاوت معنى دارى ندارند.

مختلف اما در اكثر مواقع راهكارهاى ارائه شده مثل

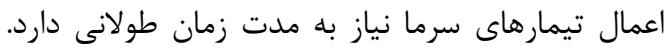

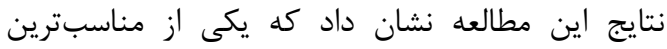

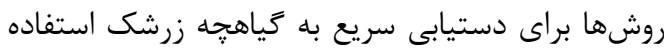

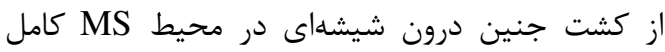

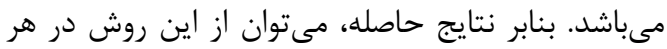

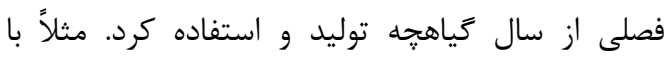

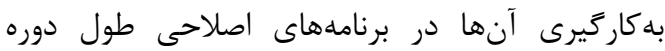
اصلاحى را كاهش داد.

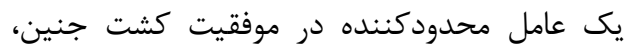
اندازه كوجى جنينها در زمان انتقال آنها به محيط

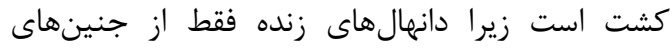

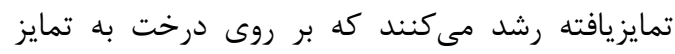

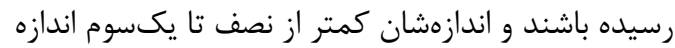
نهايى جنين نباشد (نقل از فتحى و همكاران،

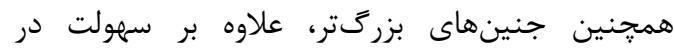
استخراج جنين، در قدرت و قابليت جوانهزنى آنها مؤثر است (نتايج نشان داده نشدند). بالا بودن دران درصد جوانهزنى براى توليد كياهجههاى سالم و يكنواخت دركشت بافت بسيار حائز اهميت است (ساخانوخو' و و بكائ

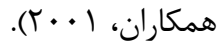
نتيجه

با وجود مطالعات گسترده در خصوص اعمال تيمارهاى مختلف براى غلبه بر خواب بذور كياهان

\footnotetext{
${ }^{1}$ Sakhanokho
} 


$$
\begin{aligned}
& \text { منابع } \\
& \text { آقايى، م. سوبا. ريز ازديادى گياه دارويى سياهدانه. يايان نامه كارشناسى ارشد. دانشگاه آزاد واحد جهرم. • 9 صفحه. } \\
& \text { رجبيان، ط.، صبورا، ع.، حسنى، ب. و فلاح حسينى، ح. ع^ґّ. اثر جيبرليك اسيد و سرمادهى بر جوانهزنى بذر آنغوزه. }
\end{aligned}
$$

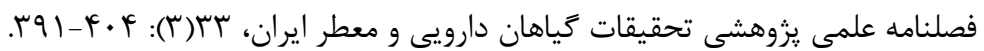

$$
\begin{aligned}
& \text { رضايى، م. و بالندرى، ا. اوس ا. بررسى اثرات استراتيفه سرمايى، اسيد جيبرليك و يوستبردارى با اسيد سولفوريك روى }
\end{aligned}
$$

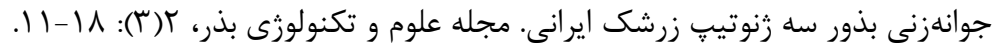

$$
\begin{aligned}
& \text { سرآبادانى تفرشى، ر.، اميدى، م.، بىهمتا، م.ر. و ميرزايى، ر. IN IV. اثر ريزنمونه و سطوح مختلف هورمونى در كالزايى و }
\end{aligned}
$$

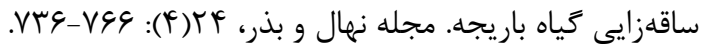

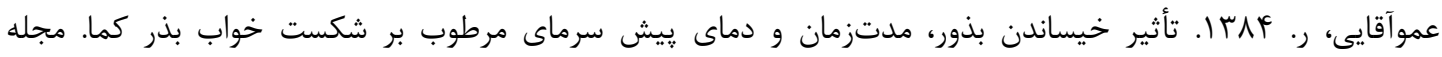

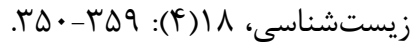

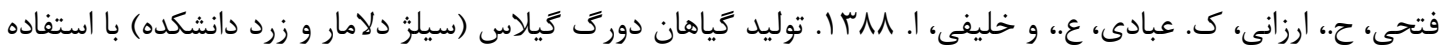

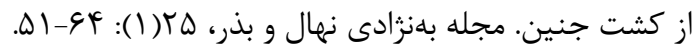

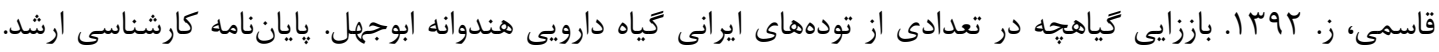

$$
\begin{aligned}
& \text { دانشخاه ياسوج. VV صفحه. } \\
& \text { قاسميان، خ.، ناظرى، س. و ميرزايىاصل، ا. • وبا. كشت جنين گياه وشا و تأثير محيط كشت و هورمون بر روى رشد آن. } \\
& \text { اولين همايش ملى مباحث نوين در كشاورزى. } \\
& \text { مرتضوى، ر.، دهدارى، ا.، معصومى اصل، ا. و فياض، ب. بوجا. بررسى كشت جنين گياه جويل در شرايط درون شيشهاى }
\end{aligned}
$$

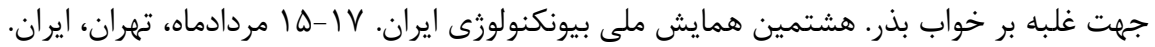

Beraak, J.P. 1978. The effect of flowering date and temperature on embryo development in sweet cherry. Netherlands Journal of Agricultural Science, 26: 13-30.

Hidayati, S.N., Baskin, J.M., and Baskin, C.C. 2001. Dormancy-breaking and germination requirements for seeds of Symphoricarpos orbiculatus (Caprifoliaceae). American Journal of Botany, 88(8): 1444-1451.

Koornneff, M., Bentsink, L., and Hilhorst, H. 2002. Seed dormancy and germination. Current Opininion in Plant Biology, 5(1): 33-36.

Mark, P.B. 1994. A review of plant embryo culture. Horticulturae Science, 29(11): 1243-1246.

Murashige, T., and Skoog, F. 1962. A revised medium for rapid growth and bio-assays with tobacco tissue cultures. Physiology of Plant, 15(3): 473-497.

Sakhanokho, H.F., Zipf, A., Rajasekaran, K., Saha, S., and Sharma, G.C. 2001. Induction of highly embryogenic calli and plant regeneration in upland and pima cotton. Crop Science, 41: 12351240

Stanys, V. 1998. Invitro techniques to increase the output of cherry seedling from earlyipening parents. Acta Horticulturae, 468: 203-208.

Susan, K., Borwn, A., Iezzoni, A.F., and Harold, W.F. 1996. Cherries spp. Horticulturae Science, 23: 213-225.

Tipirdamaz, R., and Gomurgen, N. 2000. The effects of temperature and gibberellic acid on germination of Eranthis hyemalis (L.) salisb seeds. Turkish Journal of Botany, 24(2): 143-145. 
Vieira, A.R., Vieira, M.G., Fraga, A.C. Oliveira, J.A., and Santos, C.D. 2002. Action of gibberellic acid $\left(\mathrm{GA}_{3}\right)$ on dormancy and activity of a-amylase in rice seeds. Revista Brasileira de Sementes, 24(2): 43-48.

Wei, S., Zhang, C., Chen, X., Li, X., Sui, B., Huang, H., Cui, H., Liu, Y., Zhang, M., and Guo, F. 2010. Rapid and effective methods for breaking seed dormancy in buffalobur (Solanum rostratum). Weed Science, 58(2): 141-146. 


\title{
Effect of Gibberllic Acid, Temperature and Embryo Culture on Seed Germination of Four Native Species of Barberry (Berberis spp.)
}

\author{
Zaynab Taghinezad ${ }^{1}$, Massoud Dehdari ${ }^{2,}{ }^{*}$, Amin Mirshkari ${ }^{2}$, Hossain Zaynali ${ }^{3}$ \\ ${ }^{1}$ Graduated Student of Plant Breeding, University of Yasouj \\ ${ }^{2}$ Associate and Assistant Professor, Faculty of Agriculture, University of Yasouj, Yasouj, Iran \\ ${ }^{3}$ Assistant Professor, Research center of Agriculture of Isfahan, Isfahan, Iran \\ "Corresponding author, E-mail address: adehdari@yu.ac.ir
}

(Received: 17.02.2015 ; Accepted: 26.08.2015)

\begin{abstract}
Medicinal barberry plants, belong to Berberidaceae family. Seeds of barberry have long period dormancy. Therefore, overcome to seed dormancy and increasing germination rate of seeds due to different methods will be useful. In this regard, two separate experiments were designed. In the first experiment, effect of different levels of Gibberellic acid (0, 600 and $900 \mathrm{mg} \cdot \mathrm{l}^{-1}$ at $\left.8^{\circ} \mathrm{C}\right)$ and temperatures (25 (control), 10 and $5{ }^{\circ} \mathrm{C}$ at 50 days) in a factorial experiment based on the completely randomized design with three replications and in the second experiment, effect of different nutrition concentrations of MS medium (full strength MS, 1/2MS and 1/4 MS) in a completely randomized design with three replications on embryo culture of four native species of barberry (Berberis integrima, B. vulgaris, B. crataegina and B. orthootrys) were investigated. Based on the results obtained from the first experiment, chilling treated seeds showed the greatest effect $(88 \%)$ on seed germination in comparison with gibberellic acid treatment. The results of the second experiment showed that the best MS concentration for embryo culture was full strength MS medium with\%100 seed germination in four above mentioned barberry species after 2-3 days. In general, the best method to overcome barberry seed dormancy was an embryo culture in fullstrength MS nutrition.
\end{abstract}

Keywords: Gibberellic acid, Seed dormancy, Medium culture, Medicinal plant 